$<$ fresh recto $>$

$<\mathrm{RH}(\mathrm{L}):$ Emma-Kate Matthews $>$

$<\mathrm{RH}(\mathrm{R})$ : Activating Audiences: How spatial music can help us to listen $>$

<footer: Organised Sound 24(3): 000-000 (C) Cambridge University Press 2019.>

\title{
Activating Audiences: How spatial music can help us to listen
}

EMMA-KATE MATTHEWS

The Bartlett School of Architecture, University College London, 22 Gordon St, Bloomsbury, London C1H 0QB, UK

Email: zcftfg3@ucl.ac.uk

This article discusses the importance of active listening when engaging new audiences with experimental and unfamiliar musical formats. Spatial music is examined as a physically immersive medium in which the audience is implicated as an active component in the execution of its performance. A brief account of the historic context of spatial music will be presented alongside speculation for the trajectory of its future; particularly its potential as a model for audience engagement.

This article will first consider how spatially immersive performances have the capacity to activate listeners and how can this help to engage new audiences with new ways of listening. It will also question the notion of inhabiting spatial music, with an investigation of the multiple ways in which spatial music relates to physical space and the terms of its inhabitation. The concept of virtual listening will be discussed in response to trends towards passive hearing, as driven by recent technological developments in acoustic software and hardware, and the resultant abstraction of the spatial and social dynamics of sound in virtual space. The physiological and psychological differences between listening and hearing will also be examined as a means of establishing fundamental differences in the ways that we interact with music, and questioning what our listening habits tell us about audience engagement in the context of experimental music performance. This article will also question the individual roles of the musician, composer, architect/designer and audience in the ongoing responsibility to improve audience engagement in new, or unfamiliar musical works. Importantly, this article will also explicitly examine who we are referring to when we use the term 'new audiences'

Major developments in acoustic technology during the last few decades have somewhat confused the diagram between music, space and listener. The understanding of which elements are active and which are passive is especially ambiguous at a time when ambisonic and binaural technologies have become developed enough to provide accurate simulations of the abstract, acoustic qualities of spaces, but on virtual terms. Architects, composers, musicians, engineers and audiences are at a crossroads in the development of new music and experimental, spatiosonic practice. 'Spatiosonic' is a hybrid term which is used throughout this article to describe work and phenomena which regard space (spatio) and sound (sonic) as equal, interactive partners. This article considers some of the opportunities and limitations at stake in current techniques of composition, performance and listening.

\section{LISTENING HABITS}


Sound is inherently spatial and our experience of it cannot exist without a spatial context. With regard to music, spatial context defines the terms by which the work and the listener are able to relate to each other. Music and space also have the capacity to influence each other. The relationship between space, sound source and listener is unavoidably interactive and none of the involved parties can therefore be considered truly passive.

Historically, physical architectural space has played a highly active role in influencing the experience and composition of music. The Dutch renaissance composer Adrian Willaert is famed for having supposedly invented polychoral, antiphonal music as a response to the spatially opposed positioning of choir lofts in St Mark's Basilica in Venice (Howard and Moretti 2009: 28). Conversely, architects and engineers have long acknowledged the desires of music in space. Long before Acoustics was a formally recognised discipline, Roman architect and engineer Vitruvius discusses a method for enhancing the sonic character of theatres and performance spaces by embedding acoustic vases called echea in the walls (Vitruvius 1914: 143). More recently, American composer Henry Brant converts architectural, spatial ideas into musical ones through his spatial compositions, with a view to exploring the idea that aspects of physical space (particularly distance and direction) have the capacity to be as compositionally active as the musical elements of tone and timbre (Brant, Childs and Schwartz 1967: 223-42). All these precedents acknowledge the creative potential in the dialogue between sound, space and listener.

Our usual experience of live music is conventionally frontal and static, and we sit, or stand face to face with the performers, who dutifully occupy their usual place, on the stage. When we listen to music frontally in this way, it hits us like a flat sheet and any physical distance between sound sources is imperceptible as it either does not exist in significant amounts, or its temporal effects are accounted for in the conducting of the piece. Music is similarly flattened when we listen to it on stereo headphones or stereo loudspeakers at home. The highly convenient format of stereo playback has a somewhat limited capacity to provide a sense of spatial immersion. Even with reverberant effects and downmixing from ambisonic or surround sound formats, stereo playback can only offer a reduced representation of what is otherwise a very complex and rich spatial experience. It could be argued that our typical experience of both performed and recorded music has become largely despatialised and denies the listener the interactive potential inherent in the rich reciprocal diagram between space, sound source and listener. The removal of the inter-action in this sense demotes the listener to a largely passive role. A correlation then appears to exist between the intensity of spatiosonic immersion and the level to which the listening audience are required to actively engage with the work. With this logic, we can discuss the idea that spatial music is capable of activating its listeners. But first let's define what we mean when we use the term 'spatial music'.

\section{INHABITING SPATIAL MUSIC}

Edgard Varèse once characterised spatial music as 'bodies of intelligent sounds moving freely in space' (1967: 204). The free movement that Varèse refers to here is not necessarily referring to moving sound sources, but rather to sound sources that have become liberated from their usual stagebound positions. With this notion, there is potential for the audience and the performer to occupy the same space; both are simultaneously on the stage and in the auditorium and each is as active as the other in the execution of the work. Of course, this is not a new idea and the performance of Western music has long enjoyed a rich history of spatialisation. Though the documentation of choreographic instruction for music performance is reasonably limited, manuscripts dating from the thirteenth century apparently exist where 'explicit references are made to the spatial distribution of choirs' within Rouen Cathedral (Groote 2015: 43). Though no hard 
photographic or filmic evidence of such performances could possibly exist, there is a wide range of speculation as to the desired effects of distributing musical elements between 'off-centre' spaces such as the balconies, choir lofts and side chapels of churches. In the context of ecclesiastical music, it is not unreasonable to suggest that the spatial separation of individual sounds and the possibility that their origins are out of sight had the effect of suggesting a sense of space beyond physical bounds. In this sense, the building can be considered an instrument which, when occupied, has the capacity to augment our sense of dimensional space and musical potential. Evidence that medieval church music regarded its spatial context as an active component of its delivery is recalled by acoustician and architect Hope Bagenall in an intriguing anecdote: 'A legend exists that a Mass by Fairfax - a mediaeval organist of St. Albans - was composed with a fourth part supplied by the church. Even if this was no more than a legend it shows that the building was recognised as an instrument' (Bagenall 1927: 443).

Spatial music, or, rather, music which involves the spatial separation of its individual components, is not only activating its audience, by allowing listeners to physically occupy sonic space. It is also activating the architectural, acoustical space in which it is performed, by asking the spatial organisation of the building and its material properties to support, articulate and augment musical content.

During the Renaissance, Willaert's music for cori-spezzati (separated choirs) explored an explicit resonance between spatial separation and multiple musical voices, treating the internal volume of St Mark's Basilica in Venice as an instrument which is simultaneously inhabited by audience and performer. This relationship has since been explored in the work of Charles Ives in The Unanswered Question (1906) where spatial separation is a major element in the performance of the work, as a device for articulating musical complexity and negotiating uncoordinated rhythms and polyphony. Henry Brant cites this piece as a significant influence on the composition of his own spatial pieces (Brant, Gagne, Caras and Bagnato 1982: 57). Brant produced many spatial compositions, all of which demonstrated that aspects of physical space (particularly distance and direction) can be as compositionally active as the musical elements of tone and timbre. He composed with both musical and architectural tools such as scale models, in order to simulate spatial choreographies as an integral part of the composition process. Brant's multi-disciplinary approach could be referred to as spatiosonic practice, a term which I also frequently use to describe my own compositional practice to describe work which places a specific focus on precise interactions between space and sound. Brant's high regard for physical space as an active component of music composition is acknowledged in the following quote: 'Even today (1965) the resource of space is still, by most composers, considered an optional or peripheral aspect of music ... [this view] could almost be compared to a method of composing which made no specific provision for the control of time values or pitches' (Brant et al. 1967: 223).

Since the work of Ives and Brant, it still seems that space has failed to assert a characteristic presence in mainstream musical practice, even despite attempts from more recent and high-profile experimental composers such as Karlheinz Stockhausen and lannis Xenakis. This can be observed in the behaviour and listening habits of audiences at the performances of their works. Audiences have been largely conditioned to accept their roles as passive receivers. On attending a performance of Stockhausen's Gruppen, in which three orchestral groups are placed at a distance from each other within an enclosed performance space (in this example, the Turbine Hall at the Tate Modern, London), I was witness to some unexpected behaviour. Once the piece had started, the audience began to walk around the large space of the turbine hall, albeit rather tentatively. In this moment, the audience were actively listening: moving their bodies and ears relative to the spatially diverse 
orchestral sounds and discovering the space of the music. However, around three minutes in, the movement stopped almost entirely, and the majority of the crowd began facing in the same direction, towards the central stage and largely ignoring the activity on the outer two stages, except for during very loud or distinctive moments. At this point, the audience had returned to the passive role that is so regularly assumed when experiencing frontally delivered, live music. Perhaps the reasons for this lack of consistent engagement were too many and too complex to really understand without conducting a more rigorous analysis. However, it is possible that audiences just don't know how to listen to the space of music. Spatial music has remained on the fringes of conventional music performance and audiences are not used to the idea that they are inhabiting the sound as well as receiving it.

Architect and phenomenologist Juhani Pallasmaa supports the notion that sound is like architecture and the omni-directional nature by which it propagates in space makes it habitable. He regards sound as a medium which possesses an interiority: 'sound incorporates... sound is omni-directional. The sense of sight implies exteriority, but sound creates an experience of interiority. I regard an object, but sound approaches me; the eye reaches, but the ear receives. Buildings do not react to our gaze, but they do return our sounds back to our ears' (Pallasmaa 2005: 49).

Spatial music reminds the listening audience that they are implicit in the act of listening. The audience are occupying the space and they are occupying the sound. They are not mere passive receivers as might be the typical role of the listener in the conventional experience of going to a concert, where the action takes place frontally and on a dedicated platform, or the stage, at a dimensional and social distance from the audience.

In all of my pieces: Construction 001,002 and 003, the musicians surround the audience and the music creates a series of architectural structures, made of sound, within which the audience are physically situated. Sometimes the audience is seated (as was the case with the performance of Construction 003 at the Queen Elizabeth Hall) and other times the audience is free to roam, to actively learn and discover the interactions that I have composed and curated between the music and the space. During these performances, the listeners move their bodies and their heads, to establish the origins of the sounds and try to understand how and why their positions might matter. Their increased physical (and mental) activity in this process is almost unavoidable. This is of course true of performances in both physical space and in representations of sonic and visual spaces, as rendered in virtual reality (VR), though VR is a much more portable format and need not be anchored to a specific physical place. However, in all these examples, in order to access the work, you must be inside it rather than in front of it.

If we consider the listener as an inhabitant of the music, we can then say that the music contextualises the listener, much in the same way that the architectural space contextualises the music, especially when space is used as a key component of its composition. Our experiences of hearing sound and occupying the space where it is played are not distinct from one another and when sound is displaced, or polluted with the acoustic of another space, as it would be in the playback of a recording, even with the help of ambisonic simulation and playback, it often ends up in an awkward and uncanny place. The acoustic response of immediate, physical space demands different methods of listening to the ideas of space embodied in virtual representations of recorded media. Recorded sound creates a disconnect between sound and its origins and spatial context, which in turn questions the role of space in music and therefore challenges the ability for listeners to inhabit it. Then is it fair to blame developments in recording technologies for the decontextualisation and inevitable deactivation of the listener? 


\section{VIRTUAL LISTENING}

Music and digital technology have enjoyed a productive, symbiotic relationship over the last few decades, and the virtual format of digitally recorded and distributed media now dominates our experience of this content. (Zvonar 2000) Constant improvements to the portability of recording and playback devices result in the expectation that the music we so regularly consume originally sounded anywhere except the space where we end up listening to it. We can also now easily simulate how sound might behave in spaces both existing and proposed, without ever needing to physically set foot in them.

In the book How Music Works, musician David Byrne acknowledges the evolving dialogue between technology and music, and importantly, discusses how technological developments have challenged relationships between music and the spaces in which it is experienced. Byrne discusses the invention of recorded media as a development which displaced music, from a live setting to a domestic one, having an impact on both its acoustic and social contexts: 'Music could now be completely free from any live context, or, more properly, the context in which it was heard became the living room and the jukebox - parallel alternatives to still-popular ballrooms and concert halls ... Performers adapted to this new technology' (Byrne 2012: 21).

This adaptation that Byrne refers to was also observed by producers and sound engineers, who were faced with the acoustic problem of how to represent the ambience of a performance space in the new acoustic context of the living room - and so this generated a desire to simulate spatial effects such as reverberation, to 'create the illusion of space in sound recording' (Horning 2015: 138). Spatial effects can be either recorded naturally (what I refer to as sampled space) or applied artificially in post-production as a result of an applied effect or ambisonic simulation (simulated space). I refer to both sampled and simulated space as virtual space. Virtual space defines its own context which is distinct from the acoustic and social mechanisms of immediate, or real space. With this logic, recorded music could be thought of as belonging to virtual space and live music as belonging to immediate space. As Byrne similarly identifies 'Socially and acoustically, these spaces were worlds apart' (2012: 21). In addition to these two worlds there is a third, hybrid category in which these two types of space interact, where recorded music is played in a performative (or non-domestic) setting. Byrne refers to this as 'performerless music [or] discos' (2012: 22). This format is by now very familiar, however, the potential in this overlay of spatio-acoustic realities is often overlooked. By overlay I mean that the recorded music contains the signature of a sampled or simulated space, but it is experienced in and affected by the acoustic of another. As recorded music has become such an integral part of our daily lives, we have grown accustomed to ideas of virtual space and the conceptual and acoustic complexities that arise when virtual and immediate spaces are overlaid. At this point in time, with a rich history of expertise and experience in musical, architectural and acoustical practice behind us, to ignore this somehow seems like a wasted opportunity.

In my own work, I hypothesise that the acoustic character of a performance space has the capacity to alter the structure of musical content. This was tested in my composition for Cello and Violin, titled Construction 002: Tracing. The piece is played in two acoustically contrasting settings: first, in an anechoic chamber with a total lack of acoustic response, and second, in the interior of Antoni Gaudi's Sagrada Familia, which has a highly characteristic reverberation time of 12 seconds. Musical elements that were clearly heard as distinct components of a melody in the anechoic chamber were transformed into what could only be perceived as more melodic structures in the Sagrada Familia (Figure 1). The reverberation in the Sagrada Familia was so effective that even when the musicians were standing on opposite sides of the nave, any sense of directionality was almost imperceptible, even though the distances were in excess of 60 metres (Figure 2). Even though this example presents 
a much more extreme case than the contrast between the more common situations of domestic space and concert hall, it does serve as a reminder of Bagenall's earlier observation, that buildings are instruments and their acoustic characteristics have the capacity to completely transform musical elements (mechanically speaking) and therefore our experience of them. Prior to its performance, Construction 002 was iteratively rehearsed in a digital simulation. This rendering of the sound in virtual space served as a method for predicting the behaviour of reflected sound in each of the two spaces; the results of which influenced the positioning of the musicians and the composition of the musical elements of tempo and rhythm. The simulation was useful for providing ballpark characteristics and proof of concept, however it was not until the performance occurred in physical space that the immersive qualities of the Sagrada Familia's reverberation could be experienced, and the inhabitable, visceral capacity of the music could be appreciated.

\section{[Insert Figures 1 and 2]}

The performances of all of my pieces are recorded ambisonically, as a method of documenting the work. But much like a photograph, or a point cloud from a 3D scan (Figure 3), playback of the recordings can only provide a representation of the experience, as the medium is only capable of documenting sonic content. Of course the acoustic responses of the performance spaces are embedded (or sampled) in the recordings, which in turn provides a representation of the space, on sonic terms; however, the playback of these pieces causes the music, as a composition of tonal, rhythmic, timbral and spatial elements, to become spatially de-contextualised. Brant was perhaps the best placed to support the notion that if space is an essential component of music alongside tone, timbre and rhythm, then the reduction of space to a flattened and virtual representation could be considered the equivalent of replacing a rich rhythmic idea with a metronomic pulse, or reducing the characteristic timbral qualities heard in the overtones of a cello to a simple, fundamental, pure tone. When music is spatially de-contextualised, we lose a whole dimension of its composition.

\section{[Insert Figure 3]}

The current trend towards virtual listening, as encouraged by increasingly sophisticated portable sonic devices, seems to privilege a more abstract understanding of spatiosonic phenomena. This accentuates the already significant disconnect between the interactive act of occupying sound in real spaces and what could be described as its counterpoint: the passive act of listening to representations of space, at a perceptual distance from the rich complexities of its origins.

If passive listening largely occurs at a distance from spatiosonic phenomena, then it cannot be considered part of the productive symbiosis that is present between music, space and technology, which historically results in innovative adaptation and invention, across disciplines. The dissolution of this interdisciplinary exchange would likely result in a stasis, where the practices of music and performance space design stop learning from each other; encouraging their outputs to become increasingly generic, standardised and predictable. Composers, architects, musicians and acousticians are all accountable for keeping this trans-action alive, but it is also important to remember that the listener is not excused from this responsibility. If listeners have become passive as a result of technological developments that promote a disconnection between space and music, then we need to find ways of re-activating and re-engaging our audiences. Perhaps this could start by requestioning and re-learning fundamental definitions of what it is to listen, by acknowledging the differences between listening and hearing.

\section{LISTENING AND HEARING}

French philosopher Roland Barthes draws the distinction between listening and hearing as follows: 'Hearing is a physiological phenomenon; listening is a psychological act' (Barthes 1985: 245) - 
suggesting that hearing is something that happens to us and listening is something that we have to make happen; that the potential for listening exists in the operation of hearing, but listening needs to be deliberately performed.

French composer Pierre Schaeffer similarly makes a distinction between listening (écouter) and hearing (entendre) in his discussion of the 'Four Modes of Listening' ('Les quatre écoutes'). Though, unlike Barthes's polarised model, Schaeffer's theory presents four modes of listening as a matrix, within which each of the modes are simultaneously present, to varying degrees, and in constant interaction with each other (Chion 2009: 19). Schaeffer's Matrix is perhaps a more detailed explanation of how we oscillate between various states of audible consciousness, though both Schaeffer and Barthes essentially identify the possibility that we are not necessarily always giving our full attention to everything that reaches our ears.

In the context of performed music, this notion of 'listening' vs 'hearing' implicates the audience as an active component of music, in the same way that we discussed the implications of space in music earlier on. In another parallel, Barthes also discusses the 'birth of the reader' in a literary context, in a text titled The Death of the Author. He states that 'the true locus of writing is reading ... the unity of a text is not in its origin, it is in its destination' (Barthes 1968: 6) suggesting that the content and meaning of a text (or piece of music), once committed to in writing (or performed), can only be accessed by the reader (or listener) on them actively reading and interpreting it. This is surprisingly resonant with an observation discussed by composers John Cage and Christian Wolff that musical content stored within the dormant formats of sketchbooks and scores must be 'performed' in order for the ideas to exist as a piece of music (Hicks and Asplund 2012: 95), though this example does not explicitly mention the role of the listener. We can then conclude from these two statements that in order for music to exist, it must be performed and experienced - or even better, listened to. Further to this, in order for musical ideas to exist, they must be actively listened to and interpreted by the audience. But what if this mode of listening requires a more specialist level of knowledge and expertise about the medium in order to access the levels of interpretation required to appreciate the content? And whose responsibility is it to facilitate this mode of engaged listening, especially in the context of experimental and complex works which might provide steep challenges against typical listening habits?

At this point, we are faced with a question as to whether it is the audience who should take the initiative to engage with ways of listening that are outside of the conventional and arguably passive methods, as experienced on a typical day-to-day basis; or if composers and musicians should lead this conversation by unpacking some of the more theoretical and esoteric aspects of the work, to provide a route into what might otherwise be considered an impenetrable, unfamiliar and incomprehensible world. A fair proposal for moving forward might be that a joint responsibility is established - for audiences to more actively engage with musical experiences, but with the help of musicians and composers who can teach audiences how to listen. This is seemingly especially challenging with regard to the format of spatial music, as it often requires a level of physical activity which can be difficult to coordinate and choreograph, amongst large groups of mixed backgrounds.

\section{TAKING RESPONSIBILITY}

The immediacy of a live, physical environment in conjunction with the increased level of engagement required for spatially immersive media can make audiences feel uncomfortable and even selfconscious. The portable format of recorded sound is of course much more convenient for listening to in the comfort of our own homes and privately with headphones; especially as it is now very easy to simulate ideas of space in recorded music and its playback with the use of ambisonic and binaural 
technologies. It could then be argued that a physical setting is not always necessary for performing spatial music; however, as discussed earlier, simulated, virtual space does not yet have the same immediate visceral, social and acoustically interactive capacity that real space does. With such a vast range of digital and virtual tools available at our convenience, we are in danger of forgetting this. As Byrne acknowledges: 'before recording technology existed, you could not separate music from its social context ... Music was a singular experience, something connected to a specific time and place. [Recording technology has transformed music] from something we participated in to something we consumed' (2012: 156).

Live performances in real spaces require not only an individual's presence and their physical interaction with the media, but usually also a level of social interaction with others. In conventional auditoriums, where we are all facing in the same direction and sitting or standing in our dedicated positions, the level to which we are expected to explicitly interact with others is reasonably limited as we are largely static and our efforts are focused towards the stage. However, with spatial music, we inhabit the same sonic space as the performers, and we are required to be both mentally and physically active in the experience. When the audience is used to listening to music privately, or in conventional auditorium-style settings, this more interactive format can become a source of anxiety and resistance.

Any potential for uncomfortableness amongst listeners in live, physical and immersive performance can be partially overcome by prior explanation of the format and guidance on how to listen. Before the premiere of my spatial piece for octet, titled Construction 003: Axial/Regional, I gave a short talk to my audience where I explained where they would be positioned in relation to the musicians (Figure 4) and I also gave them two key things to listen out for:

'You will notice that the musicians won't be on the stage, but instead they will be surrounding you, in the auditorium. The sound will be coming from multiple directions, so please move your heads, close your eyes and listen to the space of the music. I invite you to listen out for two distinct things. The first is to listen for axes or lines between the musicians. Try to visualise a line between the two violins, or the two violas or the two cellos when you hear them playing the same, or complementary parts. The second is to listen out for regions or areas within the auditorium where the sound becomes particularly intense. Can you hear these regions switch positions as the piece progresses? When does the sound fill the space and surround you as one large region?' (Matthews 2019)

\section{[Insert figure 4]}

I also gave the audience a chance to ask questions before and after the piece. The feedback from this pre-concert audience briefing was largely positive and a subtle reminder that composers and performers could achieve higher levels of engagement with their audiences if they explain what to listen out for and how to listen. Of course, the idea of briefing your audience is not a new revelation. Prior to the performance of Stockhausen's Helikopter-Streichquartett (1995), the audience is introduced to the musicians and the format of the performance is explained, as a means of preparing audience expectations towards a highly unconventional and unfamiliar piece.

\section{NEW AUDIENCES VERSUS OLD EXPECTATIONS}

We should now question the importance of managing audience expectations, in the context of introducing new music to new audiences. It should also be clarified who we are referring to when we use the term 'new audiences', as this title initially suggests that a new audience is any group who is broadly unfamiliar with the characteristics of the new music in question. Experimental, spatial music, by virtue of its general lack of a consistent spatial organisation and lack of reliance on conventional 
auditoria, is unavoidably a genre which challenges expected relationships between its performed output and its audience. By this logic, everyone who attends a performance of spatial, experimental music belongs to the category of new audience; however, it is not unreasonable to suggest that new audiences can be further divided between those who are familiar and comfortable with having their expectations challenged and those who are not. Of course, our expectations are generally shaped by a vast array of a lifetime's worth of experiences, tastes and complex cultural phenomena that are continually embedded in our individual psyches; however, there is an argument for suggesting that architecture plays a huge part in defining our expectations for experiences, particularly with regard to the performing arts.

Pre-concert talks and detailed programme notes are able to give us a reasonable amount of insight as to what to expect from a performance, but our expectations are usually set in motion long before we even enter the performance space. Dedicated buildings for performance - opera houses, theatres and concert halls - often have a significant physical presence in our towns and cities and their exteriors generate a strong sense of anticipation with their often distinctive and substantial massing. The Palais Garnier in Paris expresses the interior volume of the auditorium and proscenium arch in the massing of its roof as a very visible reminder of the contents of its interior. The Palais Garnier was designed by architect Jean-Louis Charles Garnier and built between 1861 and 1875 . Over a century later, a large sectional model was built by scenographer Richard Peduzzi. The sectional model very clearly exhibits the formal relationships between the volumes of the interior spaces and the expression of their massing on the exterior of the building. This architectural model is part of the permanent collection at the Musée d'Orsay, Paris. The Berliner Philharmoniker, designed by Hans Scharoun and completed in 1963, has a much more abstract massing which is formally resonant with the acoustically sympathetic geometry of its interior, and importantly, the building is situated within a designated cultural complex called the Kulturforum, a well-defined area of the city where audiences go specifically to be entertained and educated. Both of these buildings, and many more of the same typology, prepare us for being audiences. As we traverse the space between the front door and the auditorium, we go through a process of 'deactivation', which usually starts with us discarding our outerwear at the cloakroom and typically ends with us sitting silently in our designated seats, feeling a sense of removal from our usual active occupation of the city. The subtle standardisation of spatial organisation and circulation in buildings for the performing arts gradually conditions us to know how to behave, and where and when we should be positioned relative to the performers. We are very rarely expected to figure such relationships out for ourselves. This programmatic model proves to be very reliable for conventional performances, where the musicians are on the stage and the audience is seated, but what happens when unconventional performance formats meet conventional spaces; when the architecture prepares us for a typical experience, but instead we are confronted by the unexpected?

In addition to these formal, programmatic and organisational aspects, current acoustic design practice is also driving a trend towards consistency in shaping our expectations of performance spaces. Since physicist Wallace Clement Sabine developed a reliable method for calculating the reverberation time of enclosed spaces (Sabine 1922: 47), architectural acoustics has developed as a discipline which is able to abstract and formalise relationships between sound and space. Sabine's equation and the simulation tools which have since developed out of it, have enabled us to produce virtual models for predicting how sound will behave in buildings, both built and unbuilt. This ability has in turn driven a desire for acoustic certainty, especially in the practice of designing spaces for music performance. What was once largely a design process of trial and error (Forsyth 1985: 13), or in other words, a rich and productive exchange between architecture and music, has become increasingly standardised and the dialogue between these two worlds has become almost static. It is 
possible that the recent uniformity in the design of performance spaces is standardising our relationship to performed music, and this standardisation fosters a desire for certainty in performance formats amongst audiences, old and new.

Architecture then seemingly plays a crucial role in determining audience expectations, and the management of expectations is apparently important in encouraging engagement between new audiences and new music. With this in mind, it is not unreasonable to suggest that the responsibility for audience engagement, in the context of experimental music, then falls into the hands of the design professionals who define the terms of the hosting architecture. In order for architecture to respond to the unpredictable needs of experimental music performance, architects, acousticians, musicians and composers must work more synergistically to re-establish creative reciprocities between their individual disciplines. In my own research, I attempt to establish a new mode for multidisciplinary, collaborative practice between these professions, which I refer to as 'spatiosonic practice'. My compositions explore the terms by which sonic media and architectural space have the capacity to influence each other. Architecture is treated as an extension of the sound-producing instruments which play within it, and as a result, spaces are charged with the potential to become activated by musical desires. Simultaneously, performed musical compositions actively discover and exploit spatiosonic phenomena as a means of articulating musical ideas. With this model, music composition and its performance becomes a tool for maintaining a fluidity in the dialogue between musical and architectural practice. The development of this work relies heavily on audience engagement and first-hand observational feedback, as we know that scientific methods for discussing sonic phenomena operate at an objective distance from the complexity and subjectivity of experience (Romanyshyn 1989: 68). As a result, the audience for this work is inextricably implicated in its realisation and engagement is essential.

\section{CONCLUSION}

If we are to continue making new discoveries in the design and composition of sonic experiences, we must endeavour to maintain a productive reciprocity between sonic and spatial practice and in ways which are open to viewing complexity and uncertainty as sites of opportunity for innovation and exploration. In doing this, we must also remain critical of the characteristics of the spaces that we are dealing with, and understanding their capacity for audience interaction and immersion, whether we are working with virtual, real or even hybrid spatial realities.

It may be the case that spatial music, and other types of experimental sonic performance will never become mainstream, for reasons such as the often inconvenient and spatially hungry setups, or its potential to constantly explore the unfamiliar, or the potential for audience self-consciousness. However, experimental practice, in both space-making and music, is essential in order for us to continue questioning what will otherwise become accepted as known relationships and boundaries between sound and space, performer and listener and to facilitate innovation. However, experimental practitioners continually fail to engage with mainstream audiences. This results in a potential misunderstanding of the value of their work, particularly with regard to the associated creative endeavour and creation of expertise and new knowledge. If we can learn to activate our audiences, we can achieve wider and more inclusive conversations which connect specialists and non-specialists alike, thus dissolving the barrier which is commonly observed between mainstream or non-specialist audiences and unfamiliar or experimental work. As the creators of spatiosonic experiences, it is the shared responsibility of practitioners across architectural, musical and engineering disciplines to take the active role of the audience seriously and to find methods by which the more specialist aspects of the work can be more openly discussed and understood, but somehow 
without over-simplifying or compromising the complexities and subtleties that often contain the most interesting and problematic parts of such projects. With this also comes a challenge to understand how the outputs of spatiosonic practice should be appropriately documented, and how complex ideas can be clearly communicated and mutually understood across different disciplines, roles and levels of expertise. Work which is largely concerned with invisible and immediate phenomena asks some difficult questions about the role of representation. How can the more qualitative aspects of the work be discussed, without becoming overly reductive, or too abstract to be able to communicate something in an expressive, but precise manner? Does the answer lie in further technological development, or is this a point in history where we should reflect on the strengths and limitations of current tools and techniques to ask what opportunities might be lurking in hybrid solutions?

\section{REFERENCES}

Bagenall, H. 1927. Influence of Buildings on Musical Tone. Music \& Letters 8(4), 437-47.

Barthes, R. 1968. The Death of the Author, trans. R. Howard. University handout.

Barthes, R. 1985. Listening: The Responsibility of Forms, trans. R. Howard. Berkeley and Los Angeles: University of California Press.

Brant, H., Childs, B. and Schwartz, E. 1967. Space as an Essential Aspect of Musical Composition: Contemporary Composers on Contemporary Music. New York: Da Capo Express.

Brant, H., Gagne, C., Caras, T. and Bagnato, G. 1982. Soundpieces: Interviews with American Composers. London: Scarecrow Press.

Byrne, D. 2012. How Music Works. Edinburgh: Canongate Books.

Chion, M. 2009. Guide to Sound Objects: Pierre Schaeffer and Musical Research, trans. J. Dack and C. North. Paris: Institut National De L' Audiovisuel/Éditions Buchet/Chastel. http://ears.pierrecouprie.fr/spip.php?article3597 (viewed 18 May 2019).

Forsyth, M. 1985. Buildings for Music. The Architect, the Musician, and the Listener from the Seventeenth Century to the Present Day. Cambridge: Cambridge University Press.

Groote, I. 2015. Annäherungen an Hör-Räume des Mittelalters. In M. Brech, M. Paland and R. Paland (eds.) Compositions for Audible Space, the Early Electroacoustic Music and its Contexts. Bielefeld: Transcript, 27-44.

Hicks, M. and Asplund, C. 2012. Christian Wolff. Champaign, IL: University of Illinois Press.

Horning, S. 2015. Spatial Effects: Sound, Space, and Technology in Twentieth Century Popular Music. In M. Brech, M. Paland and R. Paland (eds.) Compositions for Audible Space, The Early Electroacoustic Music and its Contexts. Bielefeld: Transcript. 135-149

Howard, D. and Moretti, L. 2009. Sound and Space in Renaissance Venice: Architecture, Music, Acoustics. New Haven: Yale University Press.

Matthews, E.-K. 2019. Pre-concert talk for Construction 003: Axial/Regional. The Queen Elizabeth Hall, Southbank Centre, London.

Pallasmaa, J. 2005. The Eyes of the Skin, Architecture and the Senses. Chichester: John Wiley \& Sons Ltd. 
Romanyshyn, R,D. 1989. Technology as Symptom \& Dream. London: Routledge.

Sabine, W. 1922. Collected Papers on Acoustics. Cambridge, MA: Harvard University Press.

Stockhausen, H. 1995. Helikopter-Streichquartett - musical score. Germany: Kürten StockhausenVerlag.

Varèse, E. 1967. Spatial Music in The Liberation of Sound: Contemporary Composers on Contemporary Music, ed. Childs. B and Elliot Schwartz. E. New York: Holt Rinehart.

Vitruvius, M. 1914; orig. pub. 1486. The Ten Books on Architecture, trans. H. Morgan. Cambridge, MA: Harvard University Press.

Zvonar, R. 2000. 7.4. Multi-Channel Diffusion 2: An Extremely Brief History of Spatial Music in the 20th Century. Online Journal for Electroacoustic Practices.

https://econtact.ca/7_4/zvonar_spatialmusic.html (accessed 18 May 2019). 